\title{
CONTAMINACÃO DA ÁGUA SUBTERRÂNEA E DO SOLO POR HIDROCARBONETOS ORIUNDOS DE POSTOS DE SERVIÇOS DE BRASÍLIA, DISTRITO FEDERAL, BRASIL
}

\author{
Fernanda Viana Batista \\ Instituto Federal de Educação, Ciência e Tecnologia de Goiás (IFG) \\ Coordenação de Engenharia Ambiental e Sanitária, Goiânia, GO, Brasil \\ fernanda.gk@hotmail.com \\ Rosana Gonçalves Barros \\ Instituto Federal de Educação, Ciência e Tecnologia de Goiás (IFG) \\ Coordenação de Engenharia Ambiental e Sanitária, Goiânia, GO, Brasil \\ rosana.barros@ifg.edu.br \\ Viníciu Fagundes Bárbara \\ Instituto Federal de Educação, Ciência e Tecnologia de Goiás (IFG) \\ Coordenação de Engenharia Ambiental e Sanitária, Goiânia, GO, Brasil \\ viniciu.fagundes@ifg.edu.br
}

\begin{abstract}
RESUMO
A pesquisa objetivou quantificar hidrocarbonetos em terrenos de postos de combustíveis localizados no Cerrado brasileiro, mais especificamente em Brasília, Distrito Federal, mediante a realização de Investigações de Passivo Ambiental Detalhadas. Para tanto, 83 sondagens foram executadas em dez estabelecimentos ( $\mathrm{P}-1$ a $\mathrm{P}-10$ ) visando delimitar plumas de contaminação em fase livre, sorvida e dissolvida. No total, 117 amostras de água subterrânea e 83 de solo foram analisadas para os parâmetros benzeno, tolueno, etilbenzeno e xilenos (BTEX) e hidrocarbonetos policíclicos aromáticos (PAH). Os resultados demonstraram a inexistência de contam inação ambiental por $\mathrm{PAH}$, contudo, em $80 \%$ dos estabelecimentos foram identificados BTEX na água subterrânea e no solo, cujas maiores concentrações foram de 2.653,00 $\mu \mathrm{g} . \mathrm{L}^{-1}$ (B; P-8), 14.744,00 $\mu \mathrm{g} . \mathrm{L}^{-1}$ (T; P-7), $3.820,00 \mu \mathrm{g} . \mathrm{L}^{-1}$ (E; P-5), 29.650,00 $\mu \mathrm{g} . \mathrm{L}^{-1}(\mathrm{X} ; \mathrm{P}-5)$ para o meio hídrico subsuperficial, e de $1,18 \mathrm{mg} \cdot \mathrm{Kg}^{-1}$ (B; P-5) e 112,76 mg. $\mathrm{Kg}^{-1}$ (X; P-7) para o edáfico. São necessárias ações voltadas à proteção humana e ambiental nos terrenos contaminados, o que deve ser feito com base nas próximas etapas integrantes da Metodologia de Gerenciamento de Áreas Contaminadas (GAC).
\end{abstract}

Palavras-chave: Passivos ambientais. Combustíveis. Gerenciamento de áreas contaminadas. BTEX.PAH.

\section{GROUNDWATER AND SOIL CONTAMINATION BY HYDROCARBONS FROM SERVICE STATIONS IN BRASILIA, FEDERAL DISTRICT, BRAZIL}

\begin{abstract}
The research aimed at quantifying hydrocarbons on land at gas stations located in the Brazilian Cerrado, more specifically in Brasilia, Federal District, by conducting Detailed Environmental Liability Investigations. For this purpose, 83 surveys were carried out in ten establishments (P-1 to P-10) to delimit plumes of contamination in the free phase, sorbed and dissolved. In total, 117 groundwater samples and 83 soil samples were analysed for the parameters benzene, toluene, ethylbenzene and xylenes (BTEX) and polycyclic aromatic hydrocarbons $(\mathrm{PAH})$. The results showed no environmental contamination by $\mathrm{PAH}$; however, in $80 \%$ of the establishments, BTEX was identified in groundwater and soil, the highest concentrations of which were $2.653 .00 \mu \mathrm{g} . \mathrm{L}^{-1}(\mathrm{~B} ; \mathrm{P}-8), 14,744.00 \mu \mathrm{g} . \mathrm{L}^{-1}$ (T; P-7), $3,820.00 \mu \mathrm{g} . \mathrm{L}^{-1}(\mathrm{E} ; \mathrm{P}-5), 29,650.00 \mu \mathrm{g} . \mathrm{L}^{-1}(\mathrm{X} ; \mathrm{P}-5)$ for subsurface water, and $1.18 \mathrm{mg} \cdot \mathrm{Kg}^{-1}$ (B; P-5) and $112.76 \mathrm{mg} . \mathrm{Kg}^{-1}(\mathrm{X} ; \mathrm{P}-7)$ for soil. Actions aimed at human and environmental protection on contaminated land are necessary, which should be done based on the next steps of the GAC Methodology.
\end{abstract}

Keywords: Environmental liabilities. Fuels. Management of contaminated areas. BTEX. $\mathrm{PAH}$. 


\section{INTRODUÇÃO}

A contaminação ambiental por substâncias potencialmente perigosas ocorre devido a vários fatores, mas costuma estar associada à disposição inadequada de resíd uos e efluentes ou a vazamentos em tanques de armazenamento (MARIANO; ANGELIS; BONOTTO, 2007). Uma vez introduzidos no meio natural, contaminantes de origem antrópica capazes de causar danos aos seres vivos podem formar passivos ambientais, degradando solo, águas superficiais e subterrâneas e sedimentos, restringindo ou até mes mo impedindo o uso desses recursos naturais (BALSEIRO-ROMERO; MACIAS; MONTERROSO, 2016; ISTRATE et al., 2018).

Hidrocarbonetos derivados de petróleo, como o benzeno, tolueno, etilbenzeno, xilenos (BTEX) e os hidrocarbonetos policíclicos aromáticos (PAH) integram o grupo das substâncias ambientalmente mais preocupantes, pois apresentam maior mobilidade no meio natural e são tóxicas para diversos organismos. Por serem lipossolúveis, agem como depressores do sistema nervoso central, podendo favorecer o desenvolvimento de câncer, mutações e o envenenamento severo de populações expostas, o que levou a Organização Mundial da Saúde (OMS) a incluir esses elementos em sua lista de substâncias de elevada periculosidade (ADEYEME et al., 2009; GRANZIERA e REI, 2015; BODELÃO et al., 2017).

Segundo Hilpert et al. (2015), Teixeira; Motta; Moraes (2016), Valentyne et al. (2018) e Adipah (2019), o setor de combustíveis responde pelo maior número de áreas contaminadas no mundo. Apenas na Europa há cerca de 2,5 milhões de passivos ambientais registrados, dos quais 350.000 são oriundos de postos de serviços, sendo considerados de elevada periculosidade. Nos Estados Unidos da América (EUA), a Agência de Proteção Ambiental (USEPA) estima a existência de 571.000 tanques subterrâneos de armazenamento de combustíveis, dos quais mais de 528.000 já apresentaram algum tipo de vazamento com consequente contaminação ambiental (SAM; COULON; PRPICH, 2017). De acordo com os mesmo s autores, na Nigéria, o $12^{\circ}$ maior país produtor de petróleo do mundo, as mais de cinco décadas de exploração associadas a práticas de manejo inadequadas levaram à ampla contaminação do solo e dos recursos hídricos subterrâneos locais, tornando o Delta do Níger uma das regiões mais fortemente impactadas por hidrocarbonetos da atualidade.

Em países em desenvolvimento como o Brasil, a contaminação por derivados de petróleo advindos de Sistemas de Armazenamento Subterrâneos de Combustíveis (SASCs) de postos de serviços se constitui em uma das principais preocupações dos órgãos ambientais (FERREIRA; LOFRANO; MORITA, 2020). Apenas no Estado de São Paulo (SP), cerca de $70 \%$ dos passivos ambientais registrados são oriundos de postos, enquanto que em Minas Gerais (MG) e Rio de Janeiro (RJ), aproximadamente $80 \%$ e $60 \%$, respectivamente (ROSALES et al., 2014). De acordo com Freire; Trannin; Simões (2014), considerando que o país possui cerca de 40.000 estabelecimentos revendedores de combustíveis em operação, o potencial de contaminação associado ao setor se mostra elevado, demandando ações gerenciais específicas na busca pela sustentabilidade, as quais necessitam estar embasadas em diagnósticos capazes de caracterizar adequadamente os riscos ambientais, sociais e econômicos associados às áreas contaminadas (ITE et al., 2018).

Brasília, Capital Federal do Brasil, está localizada na Região Centro-Oeste do país, nos domínios do Cerrado, bioma de elevada biodiversidade e ecologicamente sensível (GANEM; DRUMMOND; FRANCO, 2013). Dentre os recursos naturais mais relevantes existentes no Distrito Federal (DF) estão mananciais de água doce, como o lago Paranoá e o rio Descoberto, e unidades de conservação como as Áreas de Proteção Ambiental (APAs) do Descoberto, Gama, Planalto Central e do São Bartolomeu, o que to rna a região uma área prioritária para a conservação.

Embora o comportamento de combustíveis derivados de petróleo em subsuperfície venha sendo investigado por pesquisadores (MA; RIXEY; ALVAREZ, 2013; MULLER; ROSARIO; CORSEUIL, 2013; ARAÚJO-MOURA e CAFARO FILHO, 2015; CHEN et al., 2015; AQUINO, 2016; LIMA et al., 2017), o conhecimento científico acumulado sobre o gerenciamento de áreas contaminadas (GAC) por empreendimentos comercializadores de combustíveis na região de Brasília, Capital Federal do Brasil, ainda é incipiente. Portanto, o presente estudo objetivou investigar os ef eitos da contaminação por hidrocarbonetos na água subterrânea e no solo de terrenos de postos de serviços localizados em Brasília (DF), mediante a execução de Investigações de Passivos Ambientais Detalhadas, etapa integrante da Metodologia GAC (BRASIL, 2009; CETESB, 2017). 


\section{METODOLOGIA}

Os levantamentos de campo foram realizados em dez postos de combustíveis de Brasília (denominados neste estudo de P-1 a P-10; Figura 1; Tabela 1) durante os anos de 2018 e 2019. A Capital Federal do Brasil possui $5.779,99 \mathrm{~km}^{2}, 2.974 .703$ habitantes e cerca de 300 empreendimentos comercializado res de combustíveis em operação (IBGE, 2018). A geologia regional é formada por rochas metamórficas e sedimentares, composta por quatro conjuntos litológicos e suas respectivas coberturas de solos residuais ou coluvionares: grupos Araxá, Canastra, Paranoá e Bambuí (CAMPOS, 2004).

Os estabelecimentos pesquisados foram selecionados de acordo com os seguintes critérios: estarem espacialmente distribuídos de forma a compor uma rede amostral abrangente; se localizarem em reg iõ es com elevada concentração de pessoas potencialmente expostas; se situarem nas proximidades de recursos hídricos locais, como o Lago Paranoá e o rio Descoberto, e apresentarem contaminação confirmada em etapas anteriores da Metodologia GAC, definida como o conjunto de medidas que asseguram o conhecimento das características de áreas contaminadas (BRASIL, 2009).

Atualmente, a Metodologia GAC (Figura 2) segue as diretrizes (i) da Resolução no 420/2009, instituída pelo Conselho Nacional do Meio Ambiente (CONAMA), que dispõe sobre valores orientadores de qualidade do solo quanto à presença de substâncias químicas e estabelece diretrizes para o gerenciamento de áreas contaminadas por essas substâncias em decorrência de atividad es antró picas (BRASIL, 2009); (ii) das Normas Brasileiras de Regulamentação (NBR) oํ 15.515 (ABNT, 2011a; ABNT 2011b; ABNT 2013a); 16.209 (ABNT, 2013b); 16.210 (ABNT, 2013c) e 16.784 (ABNT, 2020); e (iii) da CETESB (2017). Nesse sentido, a Investigação de Passivo Ambiental (IPA) Preliminar objetiva identificar evidências de contaminação mediante informações do histórico e das instalações do empreendimento. Nesta etapa devem ser incluídas as fontes primárias de contaminação - instalações ou materiais a partir dos quais os contaminantes se originam e foram ou estão sendo liberados para os meios impactados -, e as secundárias, constituídas pelas matrizes impactadas por substâncias químicas provenientes das fontes primárias e a partir das quais outros meios são afetados.

Figura 1 - Postos P-1 a P-10 contempladosna pesquisa, localizados em Brasília (DF), Brasil.
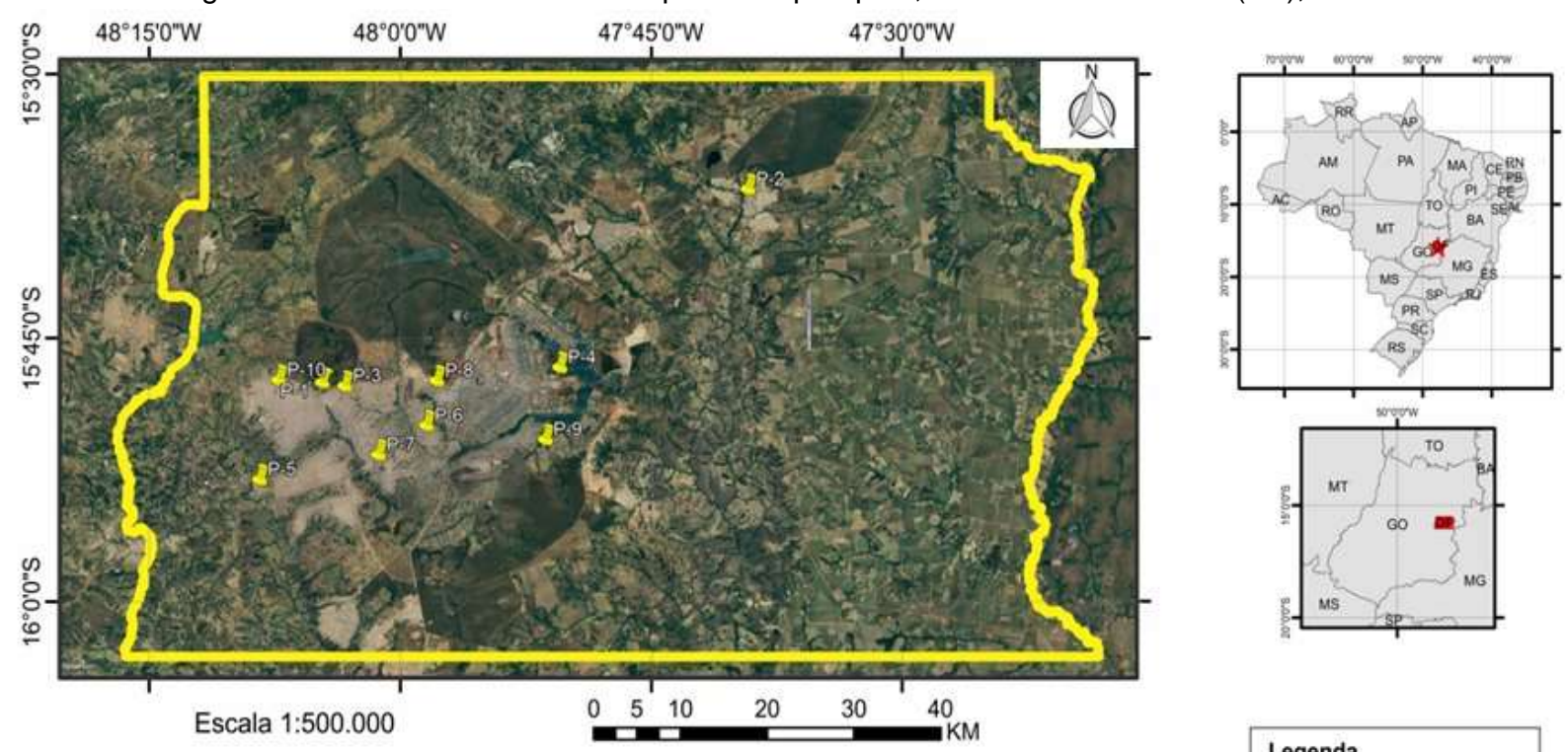

Coordinate System: GCS South American 1969 Datum: South American 1969 Units: Degree

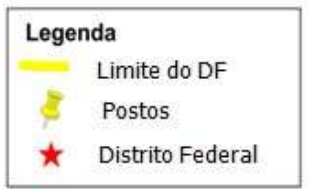

Fonte - Elaborada pelos autores. 
Tabela 1 - Características gerais dos postos de serviços de Brasília (DF) pesquisados.

\begin{tabular}{ccccccccc}
\hline POSTO & $\begin{array}{c}\text { IDADE } \\
\text { (ANOS) }\end{array}$ & $\begin{array}{c}\text { AT } \\
\left(\mathbf{m}^{2}\right)\end{array}$ & $\begin{array}{c}\text { AC } \\
\left(\mathbf{m}^{2}\right)\end{array}$ & $\begin{array}{c}\text { TQ. } \\
\text { (un.) }\end{array}$ & $\begin{array}{c}\text { ANO DE } \\
\text { FABRICAÇÃO } \\
\text { DOS TANQUES }\end{array}$ & $\begin{array}{c}\text { COMBUSTívEIS } \\
\text { COMERCIALIZADOS }\end{array}$ & $\begin{array}{c}\text { UA } \\
\text { (un.) }\end{array}$ & $\begin{array}{c}\text { UF } \\
\text { (un.) }\end{array}$ \\
\hline P-1 & 33 & 1.200 & 590 & 3 & 2009 & E/GA/GC/DC & 4 & 1 \\
P-2 & 18 & 3.552 & 531 & 3 & 2002 & E/GA/GC/DS-10 & 4 & 1 \\
P-3 & 5 & 300 & 205 & 3 & 2011 & E/GA/GC/DS-10 & 3 & 1 \\
P-4 & 20 & 3.600 & 1.100 & 3 & 2004 & E/GA/GC/DS-10 & 7 & 1 \\
P-5 & 20 & 1.314 & 602 & 4 & 2006 & E/GA/GC/DC/DS-10 & 6 & 2 \\
P-6 & 13 & 1.025 & 696 & 4 & NI & E/GA/GC/DC & 8 & 1 \\
P-7 & 7 & 1.140 & 721 & 4 & $2009 / 10$ & E/GA/GC/DC/DS-10 & 6 & 1 \\
P-8 & 20 & 3.000 & 1.928 & 4 & 2016 & E/GA/GC/DC/DS-10 & 7 & 2 \\
P-9 & 18 & 550 & 462 & 4 & NI & E/GA/GC/DC/DS-10 & 4 & 1 \\
P-10 & 14 & 900 & 361 & 3 & 2008 & E/GA/GC/DC/DS-10 & 7 & 2 \\
\hline
\end{tabular}

Legenda: AT - área total do terreno; AC - área construída;TQ - tanque; UA - unidadeabaste ce dora (bomba); UF unidade filtrante (filtro de diesel); E - etanol; GA - gasolina aditivada; GC - gasolina comum; DC - dieselcomum;DS-10 - diesel S-10; NI - não identificado; Un. - unidade.

Fonte - Elaborada pelos autores.

Figura 2 - Sequência da Metodologia GAC, com destaque para a IPA Detalhada (caixa com margem cinza), etapa contemplada neste estudo.

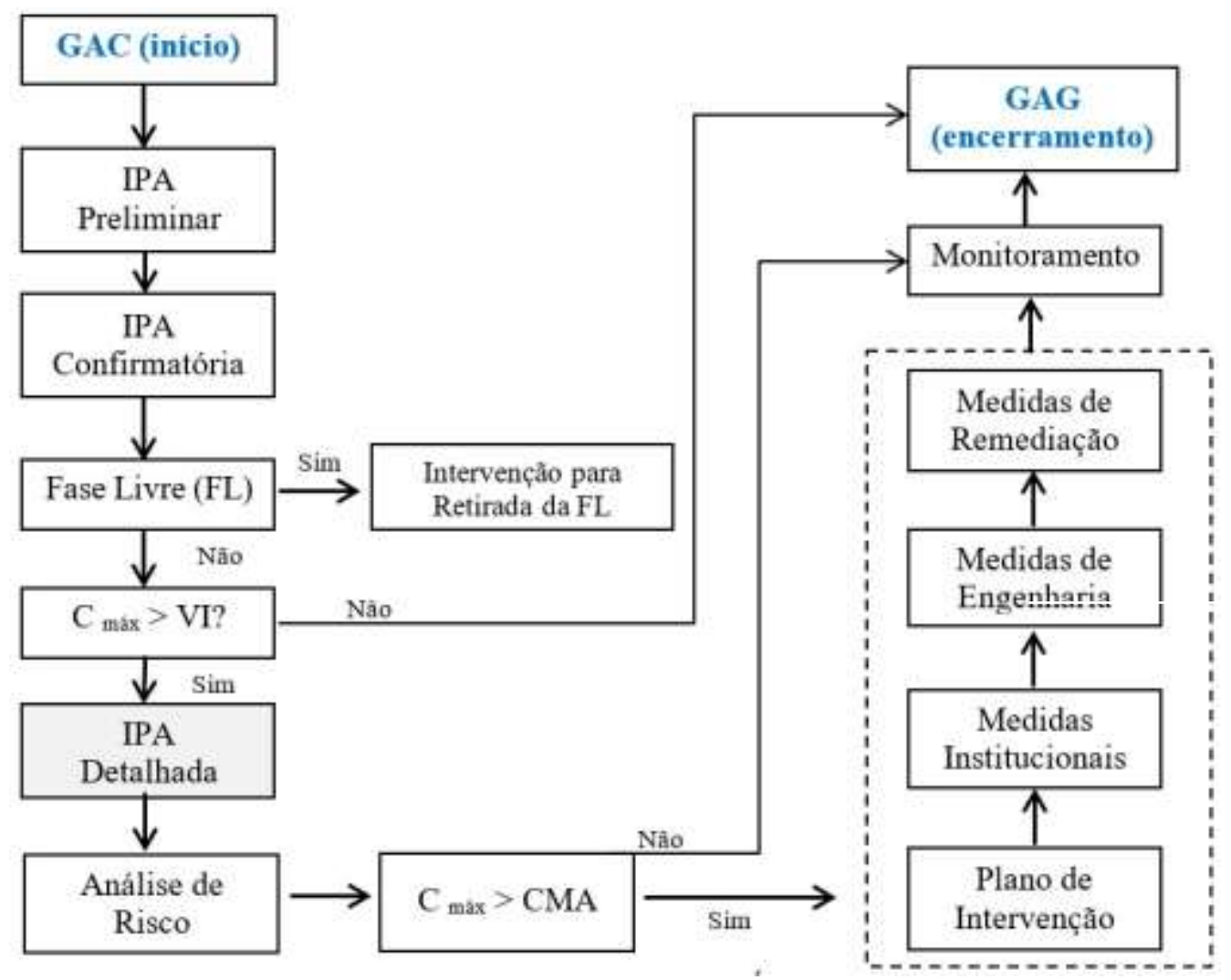

Fonte - Brasil (2009), nomas brasileiras de regulamentação e CETESB (2017), com adaptações. 
Na IPA Preliminar também devem ser realizadas medições de compostos orgânicos voláteis (VOCs) em diferentes profundidades no solo. Após essas avaliações quali-quantitativas, se constatados indícios de derivados de petróleo na subsuperfície, os levantamentos devem prosseguir para a IPA Confirmatória, que objetiva comprovar a existência de hidrocarbonetos na água subterrânea e/ou no solo acima dos valo res máximos permitidos (VMPs) por Brasil (2009). Se atestada a existência de contaminação, parte-se para a realização da IPA Detalhada. Considerada a primeira etapa do processo de recuperação de passivos ambientais, esta etapa se baseia na identificação e completa delimitação das plumas de contaminantes em fase livre (combustível in natura acumulado sobre a franja capilar por diferença de densidade), sorvid a (agrupamento de gotas de produto puro retido no solo por forças de capilaridade e adsorção) e/ou dissolvida (água subterrânea) (SÁNCHEZ, 2001; MORAES; TEIXEIRA; MAXIMIANO 2013). Na sequência, realiza-se a Análise de Risco (AR) dos cenários de exposição, que se indicar riscos, deverá resultar na elaboração do Plano de Intervenção (PI), constituído de Medidas de Engenharia, de Remediação e/ou Institucionais voltadas para a reversão do quadro de contaminação identificado. Se não detectados riscos, elabora-se o Plano de Monitoramento (PM).

Foram realizadas Investigações de Passivo Ambiental Detalhadas nos dez postos selecionados. Para tanto, realizou-se a caracterização de cada site mediante a execução de sondagens com trado manual tipo concha de 4" de diâmetro, cujas quantidades e localizações foram estrategicamente es tab elecidas com base nos resultados das investigações ambientais realizadas anteriormente (IPA Preliminar e IPA Confirmatória), nas características hidrogeológicas locais e na disposição das fontes primárias de contaminação (SASCs). Durante a execução das sondagens, amostras de solo foram coletadas a cada 1,00 m perfurado para medição das concentrações de VOCs, realizadas com um aparelho da marca GASTECH, modelo INNOVA Series, de forma que a amostra de solo referente à profundidade que acusou a maior concentração de hidrocarbonetos na forma volátil foi coletada para a realização de análises químicas de BTEX e PAH, indicadores de contaminação por gasolina e diesel, respectivamente (CE TESB, 2017). No caso de valores de VOC nulos ao longo dos perfis das sondagens, as alíquotas de solo foram obtidas junto à franja capilar, região mais próxima do lençol freático. Adicionalmente, amostras de águas subterrâneas foram obtidas nas sondagens e nos poços de monitoramento (PMs) pré-existentes, co m o auxílio de bailers de polietileno descartáveis.

Todas as amostras obtidas foram acondicionadas em frascos de vidro devidamente etiquetados, transportados em coolers com gelo $\left(4^{\circ} \mathrm{C}\right)$ até a chegada ao laboratório, terceirizado. As análises de BTEX e PAH foram realizadas com um espectrômetro de massa por cromatografia gasosa (GC-MS), em consonância com as metodologias descritas na Tabela 2. Os resultados obtidos foram comparados aos valores máximos estabelecidos por Brasil (2009).

Tabela 2 - Metodologias adotadas nas análises laboratoriais das amostras de BTEX e PAH para água subterrânea e solo, estabelecidas pela United States Environmental Protection Agency (USEPA, 2003; USEPA, 2006; USEPA, 2007; USEPA, 2014).

\begin{tabular}{ccc}
\hline MATRIZ & PARÁMETRO & METODOLOGIA ANALITICA \\
\hline \multirow{2}{*}{ Água } & BTEX & USEPA 8260C 2006 \\
& PAH & USEPA 8270 D:2014 \\
\multirow{2}{*}{ Solo } & BTEX & USEPA 5021A 2003 \\
& PAH & USEPA 3550C 2007
\end{tabular}

Fonte - Elaborada pelos autores. 
A representação gráfica das plumas de contaminação foi feita por intermédio da interpolação das linhas de isoconcentrações, com o auxílio do software AutoCAD (AUTODESK, 2011).

\section{RESULTADOS E DISCUSSÃO}

No total, 117 amostras de água subterrânea e 83 de solo foram analisadas (Tabela 3). Embora a Metodologia GAC não estabeleça o número mínimo de sondagens no âmbito de IPAs Detalhadas, suas quantidades e localizações precisam possibilitar a completa delimitação da contaminação, devendo estar embasadas na realidade ambiental de cada site investigado. Nesse sentido, critérios de decisão posicional como área do terreno, localização das fontes primárias/secundárias de contaminação em relação ao sentido preferencial de escoamento das águas subterrâneas, tipo de solo e condutividade hidráulica (MOERI; COELHO; MARKER, 2004; MOERI; RODRIGUES; NIETERS, 2007; MORAES; TEIXEIRA; MAXIMIANO, 2013; CETESB, 2017) devem ser considerados durante o estabelecimento da malha amostral. Do contrário, os resultados poderão não ser representativos do cenário investigado, tendend o a resultar em futuras decisões de gerenciamento ineficazes (LI et al., 2017).

Tabela 3 - Quantidades de amostras de água subterrânea e solo coletadas durantea realização das IPAs Detalhadas nos postos de Brasília (DF) pesquisados, e os tipos de contaminação identificada.

\begin{tabular}{|c|c|c|c|c|c|}
\hline \multirow[b]{2}{*}{ POSTO } & \multirow[b]{2}{*}{$\begin{array}{l}\text { AMOSTRAS DE } \\
\text { ÁGUA (un.) }\end{array}$} & \multirow[b]{2}{*}{$\begin{array}{l}\text { AMOSTRAS } \\
\text { DE SOLO } \\
\text { (un.) }\end{array}$} & \multicolumn{3}{|c|}{ TIPOS DE CONTAMINAÇÃOIDENTIFICADA } \\
\hline & & & $\begin{array}{l}\text { FASE LIVRE } \\
\text { (PRODUTO IN } \\
\text { NATURA) }\end{array}$ & $\begin{array}{c}\text { FASE DISSOLVIDA } \\
\text { (ÁGUA } \\
\text { SUBTERRÂNEA) }\end{array}$ & $\begin{array}{l}\text { FASE } \\
\text { SORVIDA } \\
\text { (SOLO) }\end{array}$ \\
\hline$P-1$ & 18 & 8 & Não & Não & Não \\
\hline P-2 & 13 & 13 & Não & Sim & $\operatorname{Sim}$ \\
\hline P-3 & 20 & 16 & Não & Sim & Não \\
\hline $\mathrm{P}-4$ & 11 & 8 & Não & Sim & Não \\
\hline$P-5$ & 16 & 12 & Não & Sim & Sim \\
\hline P-6 & 7 & 4 & Não & Sim & Não \\
\hline P-7 & 6 & 3 & Não & Sim & Sim \\
\hline P-8 & 20 & 7 & Não & Sim & Não \\
\hline P-9 & 6 & 6 & Não & Sim & Sim \\
\hline P-10 & NFNA & 6 & Não & Não & Não \\
\hline
\end{tabular}

Legenda:NFNA - nível freático não alcançado durante os trabalhos de campo devido ao fato do topo rochoso ser intransponível ao trado manual.

Fonte - Elaborada pelos autores.

A Tabela 3 evidencia que o P-1 e o P-10 não apresentaram contaminação, e que nenhum dos estabelecimentos pesquisados acusou ocorrência de fase livre, que, se constatada, demandaria ações imediatas de remoção do produto e atribuiria aos terrenos nessas condições a classificação de Áreas 
Contaminadas sob Intervenção (ACls) (BRASIL, 2009). Todavia, no P-2, P-5, P-7 e P-9 identificou-se fase sorvida no solo (de forma concentrada), enquanto que no P-2, P-3, P-4, P-5, P-6, P-7, P-8 e P-9 foram delimitadas plumas de contaminação do tipo fase dissolvida (Figuras 3 e 4), demonstrando que o meio mais impactado pelas contaminações foi a água subterrânea.

Figura 3 - Delimitação das plumas de fase dissolvida (representadas na cor cinza) identificadas nos postos P-1 a P-6. As setas indicam o sentido do escoamento potenciométrico.

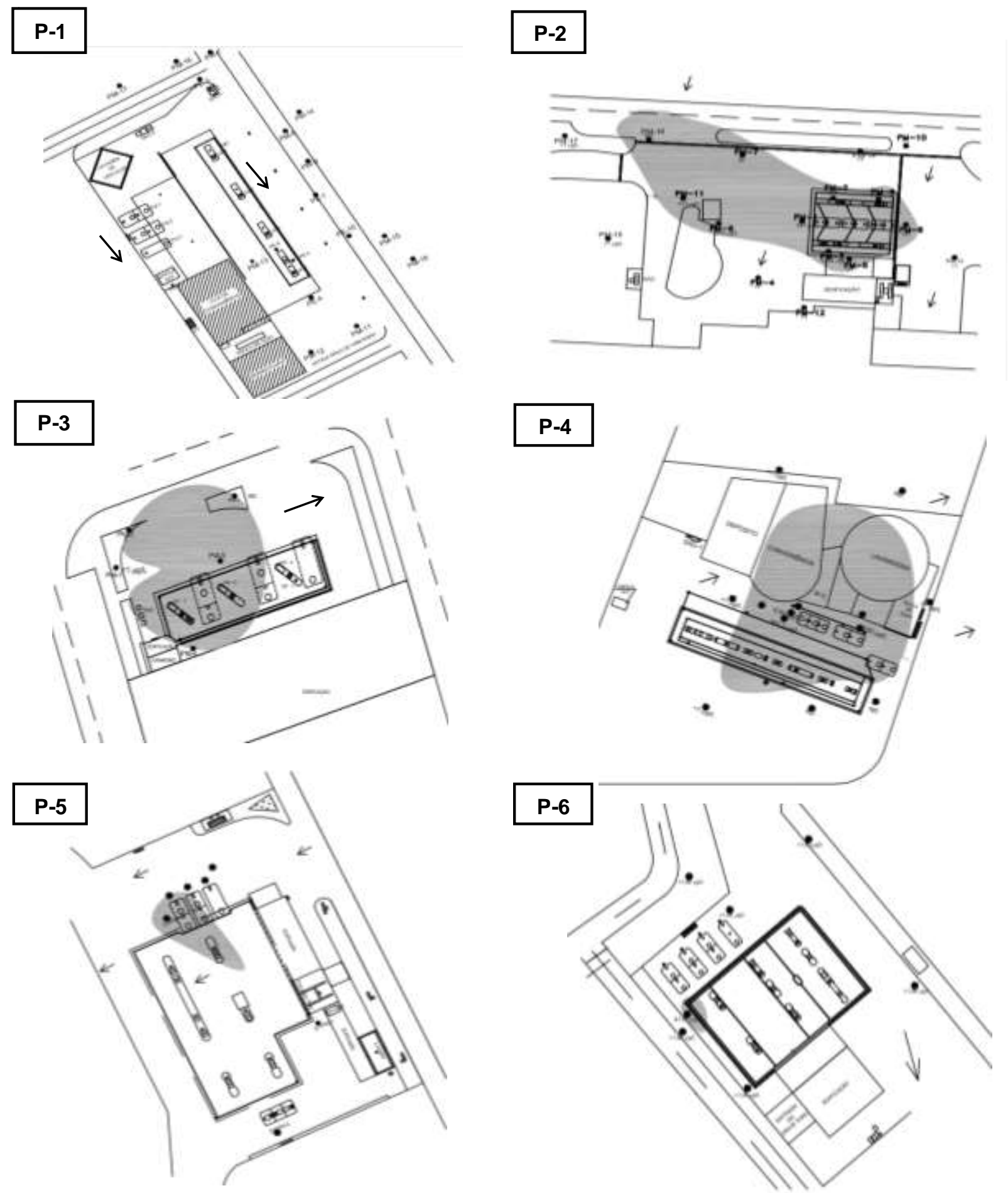

Fonte - Elaborada pelos autores. 
Figura 4 - Delimitação das plumas de fase dissolvida (representadas na cor cinza) identificadas nos postos P-7 a P-10. As setas indicam o sentido do escoamento potenciométrico.
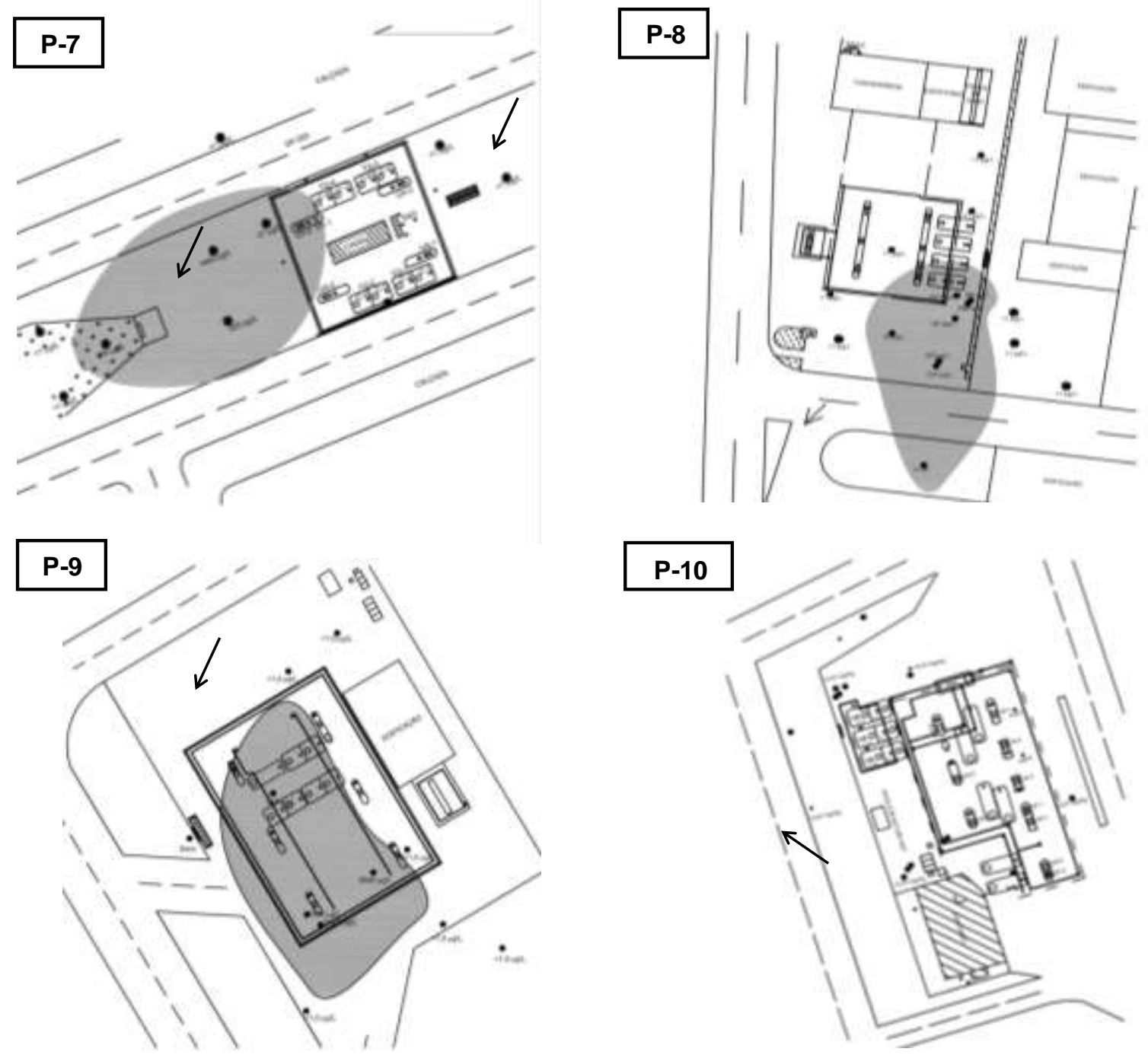

Fonte - Elaborada pelos autores.

A pluma identificada no P-6 (Figura 3) apresentou pequenas dimensões, indicando a ocorrência de contaminação em fase inicial ou de resquícios de compostos em processo final de atenuação natural. Entretanto, em todos os demais postos com presença de hidrocarbonetos dissolvidos (P - 2, P-3, P-4, P-5, $\mathrm{P}-7, \mathrm{P}-8$ e P-9) foram constatadas plumas consolidadas e de dimensões consideráveis. No caso do $\mathrm{P}-2$ e $\mathrm{P}-8$, os resultados comprovaram a existência de situações ambientalmente preocupantes, pois as plumas carreadas pelas águas subterrâneas já extrapolaram os limites dos terrenos e alcançaram espaços públicos como canteiros e vias, elevando a complexidade resolutiva dos sites. Adicionalmente, verifica-se que praticamente todas as plumas de fase dissolvida delimitadas se mostraram diretamente associadas aos tanques de armazenamento de combustíveis, fontes primárias de contaminação que neces sitam ser submetidas a constantes procedimentos de monitoramento - Testes de Estanqueidade (TE) - vis ando evitar o surgimento e/ou o agravamento de contaminações. Esse resultado era esperado e pode ser explicado pelo fato das plumas de hidrocarbonetos apresentarem intensidades mais elevadas nas imediações de fontes primárias de contaminação e menores em áreas mais distantes destas (FREIRE; TRANNIN; SIMÕES, 2014).

De acordo com Andrade; Augusto; Jardim (2010), Ramalho et al. (2013), Abdel-Shafy e Mansour (2016) e Lima et al. (2017), ao se dissolverem no meio aquoso, os hidrocarbonetos se distribuem por processos de difusão e advecção, formando plumas que são transportadas pelo fluxo hídrico e que podem extrapolar os limites dos terrenos onde se originaram, passando a oferecer riscos a bens a proteger situados fora dos sites propriamente ditos. Especificamente, uma vez introduzidos no solo e impulsionados pela força da

Caminhos de Geografia Uberlândia-MG $\quad$ v. 22, n.82 ago./2021 $\quad$ p. 256-272 Página263


gravidade, os derivados de petróleo se propagam pelas zonas insaturada e saturada, migrando verticalmente até atingirem o nível freático, formando contaminações do tipo fase sorvida, livre (devido à diferença de densidade) e/ou dissolvida (CLEARY, 1991; SÁNCHEZ, 2001; MORAES; TEIXEIRA; MAXIMIANO, 2013).

Ao pesquisarem 136 postos de Cuiabá, no Estado de Mato Grosso (MT), Lima et al. (2017) identificaram a ocorrência de contaminações do tipo fase dissolvida e sorvida em parte dos estabelecimentos investigados, tendo constatado maior comprometimento das águas subterrâneas, assim como no presente trabalho, inclusive com ocorrência de fase livre. Por outro lado, ao pesquisarem os efeitos da contaminação causada por um posto de combustíveis situado nas imediações de uma vila residencial de Porto Velho, Rondônia (RO), Forte et al. (2007) comprovaram que a pluma ating iu poços rasos localizados em casas edificadas a cerca de $50 \mathrm{~m}$ de distância do terreno onde o passivo ambiental se originou. Constatações semelhantes foram feitas por Silva et al. (2002), Mariano; Angelis; Bonotto (2007), Freire; Trannin; Simões (2014) e Vasconcelos et al. (2014).

Quimicamente, não foram identificadas concentrações de PAH em nenhuma das amostras de água e solo, entretanto, os resultados de BTEX (Figuras 5 e 6) se mostraram acima do permitido para os do is meios em praticamente todos os postos, exceto em P-1 e P-10, como já explicado.

Figura 5 - Concentrações de BTEX identificadas nas 117 amostras de água subterrânea analisadas. A escala do gráfico foi alterada para favorecer a visualização: a barracom a concentração máxima de xilenos (P-5: 29.650,00 $\left.\mu \mathrm{g} \cdot \mathrm{L}^{-1}\right)$ foi seccionada.

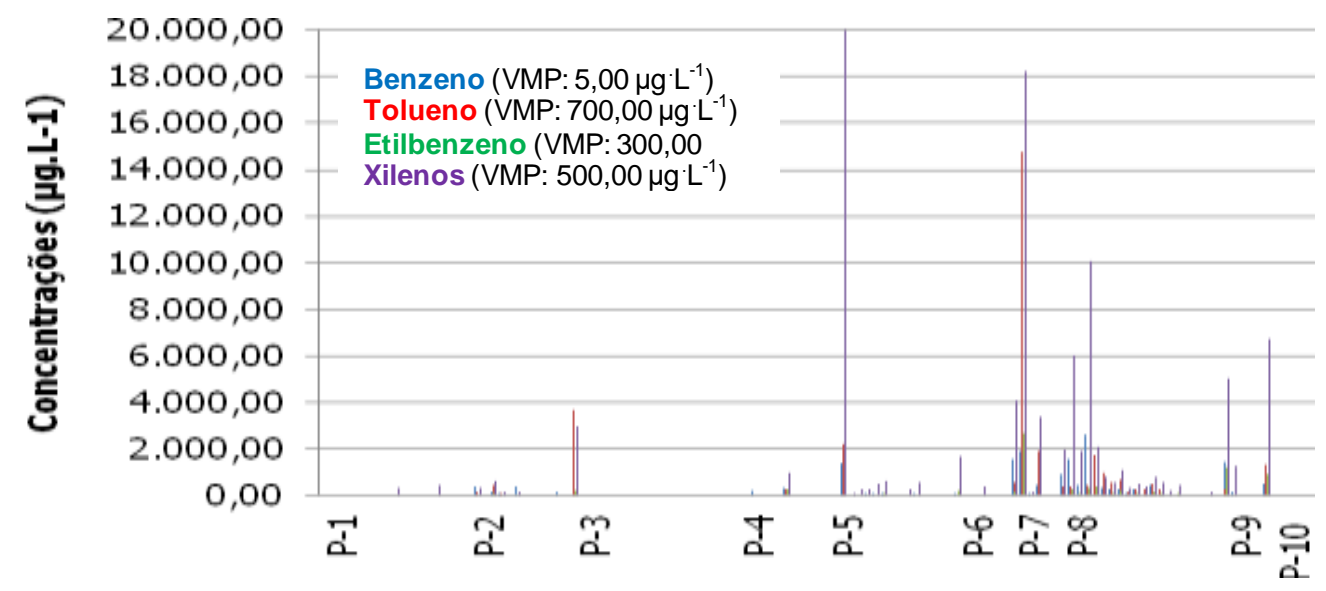

Fonte - Elaborada pelos autores.

Figura 6 - Concentrações de BTEX identificadas nas 83 amostras de solo analisadas. A escala do gráfico foialterada para favorecer a visualização: a barra com a concentração máxima de xilenos (P-7: 112,00 mg. $\left.\mathrm{Kg}^{-1}\right)$ foi seccionada.

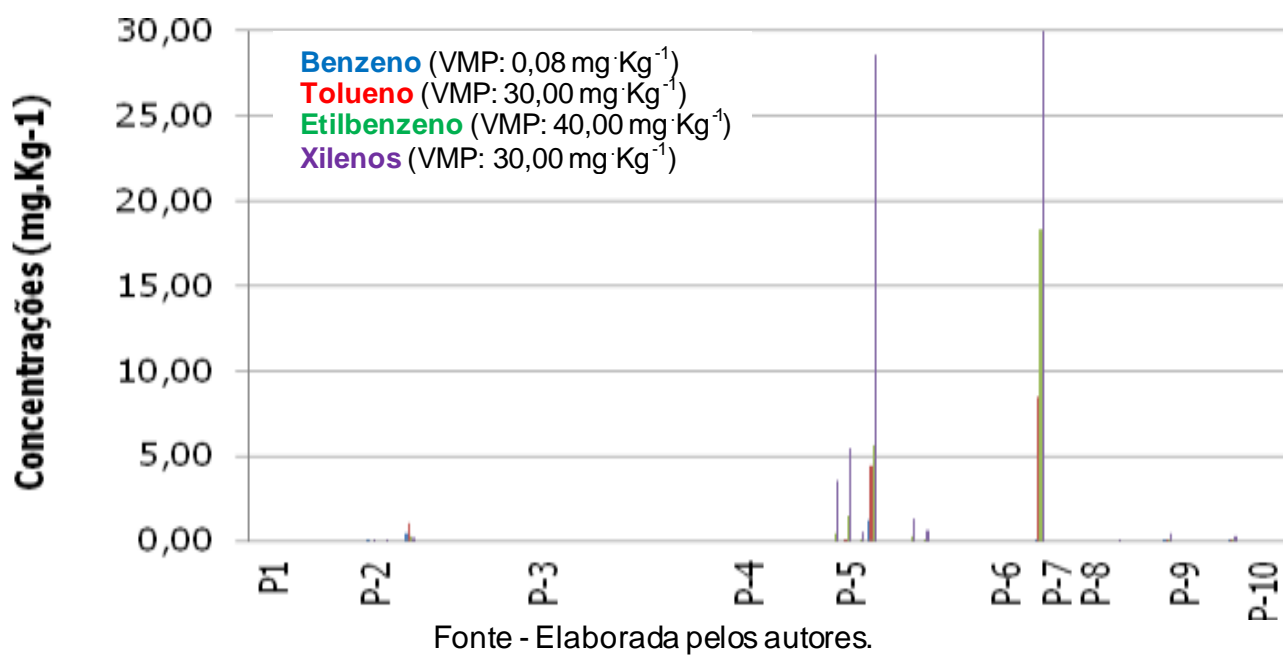


Do total das amostras de água subterrânea analisadas (Figura 5), 40 (34,19\%) acusaram co ntaminação por benzeno (P-2 ao P-9), sete (5,98\%) por tolueno (P-3, P-5, P-7, P-8 e P-9), sete $(5,98 \%)$ por etilbenzeno (P-5, P-7, P-8 e P-9) e $24(20,51 \%)$ por xilenos (P-2 ao P-9). Em relação ao solo (Figura 6$)$, constatou-se contaminação em apenas quatro amostras: três $(3,61 \%)$ por benzeno (P-2, P-5 e P-9) e uma $(1,20 \%)$ por xilenos (P-7). Este último composto se destacou entre os BTEX, pois acusou as maiores concentrações tanto para a água subterrânea $\left(29.650,00 \mu \mathrm{g} \cdot \mathrm{L}^{-1} ; \mathrm{P}-5\right)$ quanto para o solo $\left(112,00 \mathrm{mg} . \mathrm{Kg}^{-1}\right.$; P-7) (Figuras 5 e 6). A Tabela 4 apresenta mais detalhadamente as concentrações máximas de BTEX para água e solo identificadas no estudo, evidenciando que os resultados variaram centenas de vezes em relação aos VMPs estabelecidos por Brasil (2009). Verifica-se que as maiores concentrações de BTEX para a água subterrânea foram observadas no P-8 (benzeno: 2.653,00 $\mu \mathrm{g} . \mathrm{L}^{-1}$ ), no P-7 (tolueno: 14.744, 00 $\mu \mathrm{g} . \mathrm{L}^{-1}$ ) e no P-5 (etilbenzeno: $3.820,00 \mu \mathrm{g} . \mathrm{L}^{-1}$; xilenos: $29.650,00 \mu \mathrm{g} . \mathrm{L}^{-1}$ ). Para o solo, os valores mais elevados foram de 1,18 mg.Kg-1 (benzeno; P-5) e de 112,76 mg.Kg-1 (xilenos; P-7).

Tabela 4 - Resultados das concentrações máximas de BTEX identificadas nas amostras de água subterrânea e solo, oriundas dos terrenos de Brasília(DF) pesquisados. As concentrações destacadas em negrito indicam a superação dos VMPs estabelecidos por Brasil (2009).

\begin{tabular}{|c|c|c|c|c|c|}
\hline \multirow{2}{*}{ POSTO } & \multirow{2}{*}{ MEIO IMPACTADO } & \multicolumn{4}{|c|}{ MAIOR CONCENTRAÇÃO ENCONTRADA } \\
\hline & & $\mathbf{B}$ & $\mathbf{T}$ & $\mathbf{E}$ & $\mathbf{X}$ \\
\hline \multirow{2}{*}{$P-1$} & Agua $\left(\mu g \cdot L^{-1}\right)$ & $<\mathrm{LQ}$ & $<L Q$ & $<\mathrm{LQ}$ & 434,00 \\
\hline & Solo $\left(\mathrm{mg} \cdot \mathrm{Kg}^{-1}\right)$ & $<L Q$ & $<L Q$ & $<\mathrm{LQ}$ & $<\mathrm{LQ}$ \\
\hline \multirow{2}{*}{ P-2 } & Água $\left(\mu g \cdot L^{-1}\right)$ & 412,00 & 452,00 & 91,00 & 623,00 \\
\hline & Solo $\left(\mathrm{mg} . \mathrm{Kg}^{-1}\right)$ & 0,45 & 1,00 & 0,27 & 0,16 \\
\hline \multirow{2}{*}{ P-3 } & Água $\left(\mu g . L^{-1}\right)$ & $1.050,00$ & $3.659,00$ & 231,00 & $2.999,00$ \\
\hline & Solo $\left(\mathrm{mg} . \mathrm{Kg}^{-1}\right)$ & $<\mathrm{LQ}$ & $<L Q$ & $<\mathrm{LQ}$ & $<\mathrm{LQ}$ \\
\hline \multirow{2}{*}{$P-4$} & Água $\left(\mu g \cdot L^{-1}\right)$ & 362,30 & 306,30 & 252,80 & 954,56 \\
\hline & Solo (mg. $\left.\mathrm{Kg}^{-1}\right)$ & $<L Q$ & $<L Q$ & $<L Q$ & $<\mathrm{LQ}$ \\
\hline \multirow{2}{*}{ P-5 } & Água $\left(\mu g . L^{-1}\right)$ & $1.400,00$ & $2.200,00$ & $3.820,00$ & $29.650,00$ \\
\hline & Solo $\left(\mathrm{mg} \cdot \mathrm{Kg}^{-1}\right)$ & 1,18 & 4,43 & 5,59 & 28,59 \\
\hline \multirow{2}{*}{ P-6 } & Água $\left(\mu \mathrm{g} \cdot \mathrm{L}^{-1}\right)$ & 81,00 & 59,00 & 193,00 & $1.698,00$ \\
\hline & Solo $\left(\mathrm{mg} . \mathrm{Kg}^{-1}\right)$ & $<L Q$ & $<\mathrm{LQ}$ & $<L Q$ & $<L Q$ \\
\hline \multirow{2}{*}{ P-7 } & Água $\left(\mu g . L^{-1}\right)$ & $1.950,00$ & $14.744,00$ & $2.659,00$ & $18.193,00$ \\
\hline & Solo (mg. $\left.\mathrm{Kg}^{-1}\right)$ & 0,05 & 8,43 & 18,30 & 112,76 \\
\hline \multirow{2}{*}{$P-8$} & Água $\left(\mu g \cdot L^{-1}\right)$ & $2.653,00$ & $1,721,00$ & 393,00 & $10.063,00$ \\
\hline & Solo $\left(\mathrm{mg} \cdot \mathrm{Kg}^{-1}\right)$ & $<L Q$ & $<L Q$ & $<L Q$ & 0,06 \\
\hline \multirow{2}{*}{ P-9 } & Água $\left(\mu \mathrm{g} \cdot \mathrm{L}^{-1}\right)$ & $1.454,00$ & $1.311,00$ & $1.221,00$ & $6.756,00$ \\
\hline & Solo $\left(\mathrm{mg} \cdot \mathrm{Kg}^{-1}\right)$ & 0,11 & 0,07 & 0,09 & 0,46 \\
\hline \multirow{2}{*}{$P-10$} & Água $\left(\mu g . L^{-1}\right)$ & NFNA & NFNA & NFNA & NFNA \\
\hline & Solo $\left(\mathrm{mg} \cdot \mathrm{Kg}^{-1}\right)$ & $<L Q$ & $<L Q$ & $<L Q$ & $<L Q$ \\
\hline \multirow{2}{*}{\multicolumn{2}{|c|}{$\begin{array}{l}\text { Valores máximos permitidos } \\
\text { estabelecidos por Brasil (2009) }\end{array}$}} & $5 \mu \mathrm{g} \cdot \mathrm{L}^{-1}$ ou & $700 \mu \mathrm{g} \cdot \mathrm{L}^{-1} \mathrm{ou}$ & $300 \mu \mathrm{g} \cdot \mathrm{L}^{-1} \mathrm{ou}$ & $500 \mu \mathrm{g} \cdot \mathrm{L}^{-1} \mathrm{ou}$ \\
\hline & & $0,08 \mathrm{mg} \cdot \mathrm{Kg}^{-1}$ & $30 \mathrm{mg} \cdot \mathrm{Kg}^{-1}$ & $40 \mathrm{mg} \cdot \mathrm{Kg}^{-1}$ & $30 \mathrm{mg} \cdot \mathrm{Kg}^{-1}$ \\
\hline
\end{tabular}

Legenda: LQ - limite de quantificação; Var. - variável; NFNA - nível freático não alcançado em campo devido ao fato do topo rochoso ser intransponívelao trado manual.

Fonte - Elaborada pelos autores.

A constatação apenas dos compostos BTEX acima dos limites estabelecidos pelo CONAMA compro va a ocorrência de passivos ambientais formados por gasolina (BTEX), e não por diesel (PAH), constituído de cadeias de hidrocarbonetos mais longas e de menor solubilidade hídrica que a gasolina (KHAN et al., 
1996; SOUZA e CORRÊA, 2016). A predominância de cenários de contaminação por BTEX pode ser explicada pelo fato da grande maioria da frota veicular de Brasília ser constituída de automóveis movidos a gasolina (RÉQUIA JUNIOR, 2013), estocada em maiores quantidades que o diesel nos postos pesquisados, o que eleva os riscos de surgimento de passivos ambientais desencadeados por esse produto. Adicionalmente, segundo Nakhla (2003), Anneser et al. (2008) e Nwankwoala e Omofuophu (2020), em cenários de contaminação por hidrocarbonetos a maior tendência é que os BTEX se solubilizem primeiro no meio aquoso devido ao baixo coeficiente de partição octanol-ág ua, responsável pela pequena adsorção de contaminantes pelo solo e, consequentemente, pelo rápido espalhamento das plumas na zona saturada. Spiro e Stigliani (2009) complementam que esse processo pode se mostrar agravado em países onde aditivos são introduzidos na gasolina com a finalidade de aumentar o índice de octanagem veicular, como o álcool, pois proporcionam maior solubilidade dos hidrocarbonetos na água, favorecendo sua dispersão, além de dificultarem o estabelecimento de processos de atenuação natural de contaminantes pelos microrganismos (VASCONCELOS et al., 2014; LIMA et al., 2017). No Brasil, a gasolina contém entre $20 \%$ e $25 \%$ de etanol (SHIKID A e PEROSA, 2012).

Resultados semelhantes foram obtidos por Silva et al. (2002) ao pesquisarem a qualidade da água de poços rasos utilizados para abastecimento residencial na cidade de Itaguaí (RJ). Após dois anos da ocorrência de vazamentos de gasolina em um posto de serviços local, os autores identificaram concentrações de BTEX acima do permitido em pelo menos dois poços rasos. Por sua vez, Moschini; Santos; Pires (2005) realizaram um diagnóstico ambiental de 64 postos da cidade de São Carlos, Estado de São Paulo, tendo constatado contaminações que indicavam a urgência de se promover melhorias nas leis locais relacionadas ao controle e à prevenção de vazamentos em tanques de combustíveis. Na Vila Carioca, localizada na cidade de São Paulo, Cortês et al. (2011) comprovaram que uma área contaminada com BTEX desencadeou sérios problemas ambientais e sociais, dada a magnitude da contaminação associada aos recursos naturais e humanos expostos. Em Natal, Estado do Rio Grande do No rte (RN), uma equipe do Ministério Público do Rio Grande do Norte (MPRN, 2016) realizou vistorias preventivas nos 110 empreendimentos comercializadores de combustíveis da cidade objetivando identificar ind ícios de contaminação, sendo que a maior parte dos tanques em operação também era utilizada para o armazenamento de gasolina. O autor comprovou que apenas um dos estabelecimentos não apresentava vazamentos no SASC, fato que poderia desencadear sérios problemas ambientais se não fosse revertido rapidamente.

Internacionalmente, pesquisadores também obtiveram resultados semelhantes. Kumar, Sivasankar e Gopalakrishna (2017) identificaram elevadas concentrações de benzeno em fontes de água subterrânea de Madurai, uma popular cidade de peregrinação do sul da Índia, e comprovaram a existência de riscos sete vezes maiores de desenvolvimento de câncer nas crianças expostas às águas contaminadas. Ao investigarem terrenos de deposição de lodo de uma refinaria de petróleo indiana, Taraf dar e Sinha (2018) comprovaram que as populações residentes nas proximidades dos locais contaminados estavam sujeitas a elevados riscos de desenvolvimento de doenças, cabendo ao governo local a adoção de ações imediatas de gerenciamento. Em Beja e Faro, Portugal, Barberes et al. (2018) analisaram 20 amostras de solo e 31 de águas subterrâneas com o objetivo de identificar cenários de contaminação por hidrocarbonetos, tendo constatado elevados níveis de tolueno, assim como no presente trabalho, o que os levou a sugerir a interrupção do consumo de água subterrânea pela população local.

No presente estudo, a contaminação por BTEX identificada no solo e, principalmente, na água subterrânea de $80 \%$ dos estabelecimentos pesquisados ( $\mathrm{P}-2$ ao $\mathrm{P}-9$ ) também se constitui em um fato ambientalmente preocupante, dado o potencial toxicológico desses compostos, mesmo em baixas concentrações (ADEYEME et al., 2009; MOREIRA e GOMES, 2011; BALKIS; AKSU; ERSAN, 2012; AHMED e FAKHRUDDIN, 2018). Presentes na lista de poluentes prioritários da União Europeia e dos Estados Unidos da América há décadas (CHEN e CHEN, 2011; TUNSARINGKARN et al., 2012), os BTEX interagem com o ácido desoxirribonucleico (DNA), alterando sua estrutura e caus and o mutaçõ es capazes de resultar em enfermidades graves, como câncer, além de serem embriotóxicos (MOREIRA e SANTANA, 2008; SINGH e CHANDRA, 2014; CAMENZULI e FREIDMAN, 2015; ZELINKOVA e WENZL, 2015). Segundo Souza, Verssoni-Penna e Oliveira (2014) e Lee; Lee; Jeon (2019), embo ra o tolueno, o etilbenzeno e os xilenos apresentem toxicidade sistêmica de baixa a moderada, são capazes de comprometer o sistema nervoso central de organismos expostos, enquanto o benzeno, reconhecidamente o mais tóxico, é altamente mutagênico (UGOCHUKWU et al., 2018).

Os resultados obtidos nesta investigação também indicam a necessidade de serem desenvolvidas as próximas etapas da Metodologia GAC (Figura 2) nos empreendimentos que acusaram contaminação, ou seja, a elaboração de Análises de Risco seguida da implementação de Planos de Intervenção (YUAN et al., 2014; SAM; COULON; PRPICH, 2017). Segundo Valentine et al. (2018), se comprovada a

$\begin{array}{lllll}\text { Caminhos de Geografia } \quad \text { Uberlândia-MG } & \text { v. 22, n. } 82 & \text { ago./2021 } & \text { p. 256-272 } & \text { Página } 266\end{array}$


necessidade de implantação de sistemas de remediação ambiental nos estabelecimentos que acus arem riscos significativos, vários aspectos deverão ser levados em conta no momento da seleção das tecnologias mais adequadas, como taxas de biodegradação, difusão e dispersão das plumas, clima, sentido de escoamento das águas subterrâneas; tipo de solo e profundidade do nível piezométrico.

Embora estratégias de recuperação de áreas contaminadas por hidrocarbonetos sejam desafiadoras (SCHIANETZ, 1999), aspectos como percepção pública de risco, necessidade de diálogo com as comunidades afetadas e viabilidade sócio-econômica-ambiental das medidas de recuperação não devem ser desconsiderados (BRASIL, 2009; CETESB, 2017). Nesse sentido, ao contrário de países como EUA, Canadá e Japão, com maior experiência acumulada sobre o tema, o Brasil ainda carece de estratégias eficazes para a resolução de passivos ambientais, assim como a China, conforme comprovado por Li et al. (2017) em seu estudo comparativo sobre as medidas adotadas para fins de gerenciamento das áreas contaminadas existentes em 31 regiões do país. Os autores constataram que medidas resolutivas apresentavam semelhanças e diferenças dentro do próprio território chinês [assim como no Brasil], sendo necessária a implementação de um sistema objetivo e combinado com diversos instrumentos fundamentados na cooperação entre as partes interessadas, incluindo mecanismos de supervisão conjunta.

Nacionalmente, o gerenciamento de áreas contaminadas é prerrogativa exclusiva do poder estadual em muitas das Unidades Federativas, embora em alguns Estados, como Goiás (GO), esteja ocorrendo um esforço governamental para atribuir essa responsabilidade aos municípios. Especificamente no Distrito Federal, compete ao Instituo Brasília Ambiental (IBRAM) atuar nessa área, instituição que precisará exig ir a implementação das próximas etapas do GAC nos postos contaminados. Para tanto, diretrizes como adoção de ações emergenciais em casos de identificação de condições de perigo; acompanhamento da eficácia de ações emergenciais, de intervenção e de monitoramento e inclusão da situação ambiental de cada área no cadastro imobiliário local, visando dar a devida publicidade (BRASIL, 2009), precis arão ser atendidas. Nesse sentido, Sepe e Silva (2004) destacam que as decisões administrativas de gerenciamento de passivos ambientais necessitam possibilitar a obtenção de resultad os satisfatórios a curto, médio e longo prazo, o que pode ser alcançado mediante a implementação ordenada das intervenções necessárias seguida do monitoramento contínuo da eficácia e da eficiência.

\section{CONSIDERAÇÕES FINAIS}

Apesar da atividade de revenda de combustíveis ser de grande relevância para a eco nomia nacional, o setor é conhecido pelo crescente número de áreas contaminadas que desencadeia, causando impactos negativos sobre o meio ambiente e a saúde pública. Por esse motivo, demanda ações de gerenciamento ambiental específicas.

O presente estudo consistiu na realização de Investigações de Passivos Ambientais Detalhadas em dez postos de combustíveis (P-1 a P-10) localizados em Brasília, Capital Federal do Brasil, uma região do Cerrado com alta densidade populacional e dotada de importantes recursos naturais a proteger. Os resultados demonstraram a inexistência de contaminação ambiental por diesel (PAH), entretanto, em $80 \%$ dos postos investigados foram delimitadas plumas de derivados de gasolina (BTEX) nas matrizes solo (fase sorvida) e água subterrânea (fase dissolvida), esta última afetada mais intens amente. As maiores concentrações de BTEX foram de 1,18 mg. Kg-1 (benzeno; P-5) e $112,76 \mathrm{mg} \cdot \mathrm{Kg}^{-1}$ (xilenos; P-7) para o

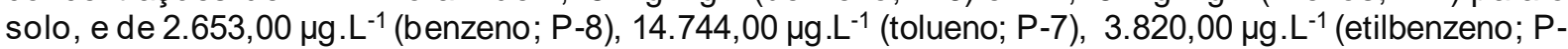
5), 29.650,00 $\mu \mathrm{g} . \mathrm{L}^{-1}$ (xilenos; P-5) para a água subterrânea. Diante desse cenário, é necessária a ad oção de medidas efetivas voltadas para a proteção humana e ambiental, o que deverá ser f eito com base no desenvolvimento das próximas etapas da Metodologia GAC.

\section{AGRADECIMENTOS}

Ao Instituto Federal de Educação, Ciência e Tecnologia de Goiás (IFG), campus Goiânia, e à TECPAM Tecnologia e Planejamento Ambiental.

\section{REFERÊNCIAS}

ABDEL-SHAFY, H. I.; MANSOUR, M. S. M. A review on polycyclic aromatic hydrocarbons: source, environmental impact, effect on human health and remediation. Egyptian Journal of Petroleum, v.25, n.1, p.107-123, 2016. https://doi.org/10.1016/j.ejpe.2015.03.011

$\begin{array}{lllll}\text { Caminhos de Geografia } \quad \text { Uberlândia-MG } & \text { v. 22, n. } 82 & \text { ago./2021 } & \text { p. 256-272 } & \text { Página } 267\end{array}$


ABNT - Associação Brasileira de Normas Técnicas. Norma NBR 15.515: Passivo ambiental em solo e água subterrânea - parte 1 - Avaliação Preliminar. São Paulo, 2011a.

Norma NBR 15.515: Passivo ambiental em solo e água subterrânea - parte 2 - Investigação Confirmatória. São Paulo, 2011b.

Norma NBR 15.515: Passivo ambiental em solo e água subterrânea - parte 3 - Investigação Detalhada. São Paulo, 2013a.

Norma NBR 16.209: Avaliação de risco a saúde humana para fins de gerenciamento de áreas contaminadas. São Paulo, 2013b.

Norma NBR 16.210: Modelo conceitual no gerenciamento de áreas contaminadas Procedimento. São Paulo, 2013c.

Norma NBR 16.784: Reabilitação de áreas contaminadas - Plano de Intervenção: procedimento de elaboração. São Paulo, 2020.

ADEYEME, O.; AJAYI, O.; OLAJUYIN, A. M.; OLOYEDE, O. B.; OLADIJI, A. T.; OLUBA, O. M.; ADEYEMI, O.; OLOLADE, A.; ADEBAYO, A. Toxicological evaluation of the effect of water contaminated with lead, phenol and benzene on liver, kidney and colon of Albino rats. Food and Chemical Toxicology, v.47, n.4, p.885-887, 2009. https://doi.org/10.1016/j.fct.2009.01.023

ADIPAH, S. Introduction of petroleum hydrocarbons contaminants and its human effects. Journal of Environmental Science and Public Health, v.3, n.1, p.001-009, 2019.

AHMED, F.; FAKHRUDDIN, A. N. M. A review on environmental contamination of petroleum hydrocarbons and its biodegradation. International Journal of Environmental Sciences \& Natural Resources, v.11, n.3, p.1-7, 2018.

ANDRADE, J. A.; AUGUSTO, F.; JARDIM, I. C. S. F. Biorremediação de solos contaminados por petróleo e seus derivados. Eclética Química, v.35. n.3. p.17-43. 2010. https://doi.org/10.1590/S010046702010000300002

ANNESER, B.; EINSIEDL, F.; MECKENSTOCK, R. U.; RICHTERS, L.; WISOTZKY, F.; GRIEBLER, C. High-resolution monitoring of biogeochemical gradients in a tar oil-contaminated aquifer. Applied Geochemistry, v.23, n.6, p.1715-1730, 2008. https://doi.org/10.1016/j.apgeochem.2008.02.003

AQUINO, A. Perícia ambiental em postos revendedores de combustíveis. Rio de Janeiro: UERJ, 2016. https://doi.org/10.6008/SPC2179-6858.2016.002.0017

ARAÚJO-MOURA, A. A. C.; CAFARO FILHO, R. A. Panorama do gerenciamento de áreas cont aminadas no Brasil após a Resolução CONAMA 420/09. Águas Subterrâneas, v.29, n.2, p.202-212, 2015. https://doi.org/10.14295/ras.v29i2.27972

AUTODESK Inc. AutoCAD. Autodesk Knowledge. 2011.

BALKIS, N.; AKSU, A.; ERSAN, M. Petroleum hydrocarbon contamination of the Southern Black Sea Self, Turkey. Environmental Science and Pollution Research, v.19, n.2, p.592-599, 2012. https://doi.org/10.1007/s11356-011-0583-4

BALSEIRO-ROMERO, M.; MACIAS, F.; MONTERROSO, C. Characterization and fingerprinting of soil and groundwater contamination sources around a fuel distribution station in Galicia (NW Spain).

Environmental Monitoring Assessment, v.188, n.5, p.1-15, 2016. https://doi.org/10.1007/s10661-0165288-1

BARBERES, G. A.; DOS REIS, R. P.; SPIGOLON, A. L. D.; FONSECA, P. E.; DE MELLO, C. B.; BARATA, M. T. Groundwater natural contamination by toluene in Beja and Faro Districts, Portugal . Geosciences, v.8, n.1, p.1-18, 2018. https://doi.org/10.3390/geosciences8010009

BODELÃO, T. G.; OLIVEIR, E.; FREITAS, J. G.; SATO, M. A.; FURQUIM, S. C. A. Importância dos horizontes do solo na distribuição de gasolina com etanol na zona não saturada em solo tropical. Águas Subterrâneas, v.31, n.4, p.413-422, 2017. https://doi.org/10.14295/ras.v31i4.28924

BRASIL. Resolução no 420, de 28 de dezembro de 2009. Dispõe sobre critérios e valores orientadores de qualidade do solo quanto à presença de substâncias químicas e estabelece diretrizes para o gerenciamento ambiental de áreas contaminadas por essas substâncias em decorrência de atividades antrópicas. Diário Oficial da União, Brasília, DF, n. 249, p. 81 - 84, 30 dezembro 2009. 
CAMENZULI, D.; FREIDMAN, B. L. On-site and in situ remediation technologies applicable to petroleum hydrocarbon contaminated sites in the Antarctic and Arctic. Polar Research, v.34, n.1, p.1-19, 2015. https://doi.org/10.3402/polar.v34.24492

CAMPOS, J. E. G. Hidrogeologia do Distrito Federal: bases para a gestão dos recursos hídricos subterrâneos. Revista Brasileira de Geociências, v.34, n.1, p.41-48, 2004.

https://doi.org/10.25249/0375-7536.20043414148

CETESB - Companhia de Tecnologia de Saneamento Ambiental do Estado de São Paulo. Decisão de Diretoria no 038/2017/C. São Paulo: CETESB, 2017.

CHEN, C. S.; SHU, Y. Y.; WU, S. H.; TIEN, C. J. Assessing soil and groundwater contamination from biofuel spills. Environmental Science Processes \& Impacts, v.17, n.3, p.533-542, 2015. https://doi.org/10.1039/C4EM00443D

CHEN, C. W.; CHEN, C. F. Distribution, origin, and potencial toxicological significance of polycyclic aromatic hydrocarbons (PAHs) in sediments of Kaohsiung Harbor, Taiwan. Marine Polution Bulletin, v.63, p.417-423, 2011. https://doi.org/10.1016/j.marpolbul.2011.04.047

CLEARY, R. Águas subterrâneas. São Paulo: ABES, 1991.

CORTÊS, P. L.; ALVES FILHO, A. P.; RUIZ, M. S.; TEIXEIRA, C. E. A deposição de resíduos industriais organoclorados no litoral do Estado de São Paulo: um estudo de caso. Revista de Administração e Inovação, v.8, p.131-163, 2011. https://doi.org/10.5773/rai.v8i2.700

FERREIRA, R. M.; LOFRANO, F. C.; MORITA, D. M. Remediação de áreas contaminadas: uma avaliação crítica da legislação brasileira. Engenharia Sanitária e Ambiental, v.25, n.1, p.115-125, 2020. https://doi.org/10.1590/s1413-41522020168968

FORTE, E. J.; AZEVEDO, M. S.; OLIVEIRA, R. C.; ALMEIDA, R. Contaminação de aqüífero por hidrocarbonetos: estudo de caso na Vila Tupi, Porto Velho - Rondônia. Química Nova, v.30, n.7, p.15391544, 2007. https://doi.org/10.1590/S0100-40422007000700008

FREIRE, P. A. C.; TRANNIN, I. C. B.; SIMÕES, S. J. Bombeamento e tratamento da fase livre em aquíf ero litorâneo. Engenharia Sanitária e Ambiental, v.19, n.4, p.461-470, 2014. https://doi.org/10.1590/S141341522014019000000122

GANEM, R. S.; DRUMMOND, J. A.; FRANCO, J. L. A. Conservation polices and control of habitat fragmentation in the Brazilian Cerrado biome. Ambiente e Sociedade, v. 16, n.3, p.99-118, 2013. https://doi.org/10.1590/S1414-753X2013000300007

GRANZIERA, M. L. M; REI, F. Energia e meio ambiente: contribuições para o necessário diálogo. São Paulo: Universitária Leopoldianum, 2015.

HILPERT, M.; MORA, B. A.; NI, J.; RULE, A. M.; NACHMAN, K. E. Hydrocarbon release during fuel storage and transfer at gas stations: environmental and health effects. Current Environmental Health Reports, v.2, n.4, p.412-422, 2015. https://doi.org/10.1007/s40572-015-0074-8

IBGE - Instituto Brasileiro de Geografia e Estatística. Perfil dos municípios brasileiros. Rio de Janeiro: IBGE, 2018.

ISTRATE, I. A.; COCÂRTÅ, D. M.; WU, Z.; STOIAN, M. A. Minimizing the health risks from hydrocarbon contaminated soils by using Electric Field-Based Treatment for soil remediation. Sustainability, n.10, p.113, 2018. https://doi.org/10.3390/su10010253

ITE, A. E.; HARRY, T. A.; OBADIMU, C. O.; ASUAIKO, E. R.; INIM, I. J. Petroleum hydrocarbons contamination of surface water and groundwater in the Niger Delta Region of Nigeria. Journal of Environment Pollution and Human Health, v.6, n.2, p.51-61, 2018. https://doi.org/10.12691/jephh-6-2$\underline{2}$

KHAN, A. A.; COPPOCK, R. W.; SCHULER, M. M.; FLORENCE, L. Z.; LILLIE, L. E.; MOSTROM, M. S. Biochemical effects of pembina cardium crude oil exposure in Cattle. Archives of Environmental Contamination and Toxicology, v.30, p.349-355, 1996. https://doi.org/10.1007/s002449900047 KUMAR, M. S.; SIVASANKAR, V.; GOPALAKRISHNA, G. V. T. Quantification of benzene in groundwater sources and risk analysis in a popular South Indian Pilgrimage City - a GIS based approach. Arabian Journal of Chemistry, v.10, n.2, p.2523-2533, 2017. https://doi.org/10.1016/j.arabjc.2013.09.022 
LEE, Y.; LEE, Y.; JEON, C. O. Biodegradation of naphthalene, BTEX, and aliphatic hydrocarbons by Paraburkholderia aromaticivorans BN5 isolated from petroleum-contaminated soil. Scientifics Reports, v.9, n.860, p.1-13, 2019. https://doi.org/10.1038/s41598-018-36165-x

LI, X.; JIAO, W.; XIAO, R.; CHEN, W.; LIU, W. Contaminated sites in China: countermeasures of provincial governments. Journal of Cleaner Production, v.147, n.20, p.485-496, 2017.

https://doi.org/10.1016/j.jclepro.2017.01.107

LIMA, S. D.; DE OLIVEIRA, A. F.; GOLIN, R.; CAIXETA, D. S.; DE LIMA, Z. M.; DE MORAIS, E. B. Gerenciamento de áreas contaminadas por postos de combustíveis em Cuiabá, Mato Grosso, Brasil. Revista Ambiente \& Água, v.12, n.2, p.300-315, 2017. https://doi.org/10.4136/ambi-agua. 1872

MA, J.; RIXEY, W. G.; ALVAREZ, P. J. J. Microbial processes influencing the transport, fate and groundwater impacts of fuel ethanol releases. Current Opinion in Biotechnology, v.24, n.3, p.457-466, 2013. https://doi.org/10.1016/..copbio.2012.09.005

MARIANO, A. P.; ANGELIS, D. F.; BONOTTO, D. M.; Monitoramento de indicadores geoquímicos e avaliação de biodegradação em área contaminada com óleo diesel. Engenharia Sanitária e Ambiental, v.12, n.3, p.296-304, 2007. https://doi.org/10.1590/S1413-41522007000300009

MOERI, E.; COELHO, R.; MARKER, A. Remediação e revitalização de áreas contaminadas: aspectos técnicos, legais e financeiro. São Paulo: Signus, 2004.

MOERI, E. N.; RODRIGUES, D.; NIETERS, A. Áreas contaminadas: remediação e revitalização. São Paulo: Signus, 2007.

MORAES, S. L.; TEIXEIRA, C. E.; MAXIMIANO, A. M. S. Guia de elaboração de Planos de Intervenção para o gerenciamento de áreas contaminadas. São Paulo: IPT, 2013.

MOREIRA, G. M.; GOMES, S. F. Intoxicação ocupacional pelo benzeno: um assunto de saúde ambiental. Revista Brasileira de Odontologia, v.68, n.2, p.171-174, 2011.

MOREIRA, V. L.; SANTANA, G. P. Estudo sobre o conhecimento dos mecânicos de manaus acerca dos problemas causados por hidrocarbonetos combustíveis e lubrificantes usados nas oficinas mecânicas.

Revista Caminhos de Geografia, v.9, n.26, p.185-205, 2008.

MOSCHINI, L. E.; SANTOS, J. E.; PIRES, J.S. R. Environmental diagnosis of risk areas related to gas stations. Brazilian Archives of Biology and Technology, v.48, n.4, p.657-666, 2005.

https://doi.org/10.1590/S1516-89132005000500019

MPRN - Ministério Público do Estado do Rio Grande do Norte. Adequação ambiental de postos de combustíveis de Natal e recuperação da área degradada. Natal: MPRN, 2016.

MULLER, C. C.; ROSARIO, M.; CORSEUIL, H. X. Investigações forenses e a estimativa da idade da fonte em áreas contaminadas por gasolina com etanol. Águas Subterrâneas, v.27, n.3, p.88-100, 2013.

https://doi.org/10.14295/ras.v27i3.27418

NAKHLA, G. Biokinetic modeling of in situ bioremediation of BTX compounds -impact of process variables and scaleup implications. Water Research, v.37, n.6, p.1296-1307, 2003. https://doi.org/10.1016/S00431354(02)00491-8

NWANKWOALA, H. O.; OMOFUOPHU, E. Investigation of hydrocarbon contaminant levels and groundwater quality assessment in parts of Bonny island, rivers state of Nigeria. Central Asian Journal of Environmental Science and Technology Innovation, v.1, p.61-70, 2020.

RAMALHO, A. M. Z.; SOBRINHO, H. L. A.; ANJOS, R. B.; DANTAS, T. N. C.; DA SILVA, D. R. Study of contamination by benzene due diesel and gasoline leaks at a gas station in Natal/Brazil. International Journal of Engineering \& Technology, v. 14, n.2, p.49-54, 2013.

RÉQUIA JUNIOR, W. J. Frota de veículos automotores e seca do Distrito Federal: os efeitos sobre a saúde pública. InterfacEHS, v.8, n.3, p.123-137, 2013.

ROSALES, R. M.; MARTíNEZ-PAGÁN, P.; FAZ, A.; BECH, J. Study of subsoil in former petrol stations in SE of Spain: physicochemical characterization and hydrocarbon contamination assessment. Journal of Geochemical Exploration, v.147, p.306-320, 2014. https://doi.org/10.1016/j.gexplo.2014.10.006 
SAM, K.; COULON, F.; PRPICH, G. Management of petroleum hydrocarbon contaminated sites in Nigeria: current challenges and future direction. Land Use Policy, v.64, p.133-144, 2017.

https://doi.org/10.1016/j.landusepol.2017.01.051

SÁNCHEZ, L. E. Desengenharia: o passivo ambiental na desativação de empreendimentos industriais. São Paulo: EDUSP, 2001.

SCHIANETZ, B. Passivos ambientais. Curitiba: FIEP, CIEP, SESI, SENAI e IEL, 1999.

SEPE, P. M.; SILVA, F. A. N. Remediação e revitalização de contaminadas: aspectos técnicos, legais e financeiros. São Paulo: SIGNUS, 2004.

SHIKIDA, P. F. A.; PEROSA, B. B. Álcool combustível no Brasil e path dependence. Revista de Economia e Sociologia Rural, v.50, n.2, p.1-20, 2012. https://doi.org/10.1590/S010320032012000200003

SILVA, R. L. B.; BARRA, C. M.; MONTEIRO, T. C. N.; BRILHANTE, O. M. Estudo da contaminação de poços rasos por combustíveis orgânicos e possíveis consequências para a saúde pública no município de Itaguaí, Rio de Janeiro, Brasil. Cadernos de Saúde Pública, v.18, n.6, p.1599-1607, 2002. https://doi.org/10.1590/S0102-311X2002000600014

SINGH, K.; CHANDRA, S. Treatment of petroleum hydrocarbon polluted environment through bioremediation: a review. Pakistan Journal of Biological Sciences, v.17, n.1, p.1-8, 2014. https://doi.org/10.3923/pibs.2014.1.8

SOUZA, C. V.; CORRÊA, S. M. Polycyclic aromatic hydrocarbons in diesel emission, diesel fuel and lubricant oil. Fuel, v.185, n.1, p.925-931, 2016.

SOUZA, E. C.; VERSSONI-PENNA, T. C.; OLIVEIRA, R. P. S. Biosurfactant-enhanced systems contaminated with petroleum hydrocarbons and ethanol. Water Research, v.32, p.654-660, 2014. https://doi.org/10.1016/j.fuel.2016.08.054

SPIRO, T. G.; STIGLIANI, W. M. Química ambiental. São Paulo: Pearson Prentice Hall, 2009.

TARAFDAR, A.; SINHA, A. Public health risk assessment with bioaccessibility considerations for soil PAHs at oil refinery vicinity areas in India. Science of the Total Environment, v.616-617, p.1477-1484, 2018. https://doi.org/10.1016/j.scitotenv.2017.10.166

TEIXEIRA, C. E.; MOTTA, F. G.; MORAES, S. L. Panorama GAC: mapeamento da cadeia de gerenciamento de áreas contaminadas. São Paulo: IPT, 2016.

TUNSARINGKARN, T.; SIRIWONG, W.; RUNGSIYOTHIN, A.; NOPPARATBUNDIT, S. Occupational exposure of gasoline station workers to BTEX compounds in Bangkok, Thailand. International Journal Occupation Environmental Medicine, v.3, n.3, p.117-25, 2012.

UGOCHUKWU, U. C.; OCHONOGOR, A.; JIDERE, C. M.; AGU, C.; NKOLOAGU, F.; EWOH, J.; OKWUDELUNZU, V. U. Exposure risck to polycyclic aromatic hydrocarbons by humans and lives tock (cattle) due to hydrocarbon spill from petroleum products in Niger-delta wetland. Environment International, v.115, p.38-47, 2018. https://doi.org/10.1016/j.envint.2018.03.010

USEPA - United States Environmental Protection Agency. Volatile organic compounds in various sample matrices using equilibrium headspace analysis. USEPA/5021A. 2003.

. Volatile organic compounds by gas chromatography/mass spectrometry (GC/MS).

USEPA/8260C. 2006.

Ultrasonic extraction. USEPA/3550C. 2007.

2014.

Semivolatile organic compounds by gas chromatography/mass spectrometry. USEPA/8270D.

VALENTYNE, A.; CRAWFORD, K.; COOK, T.; MATHEWSON, P. D. Polycyclic aromatic hydrocarbon contamination and source profiling in watersheds serving three small Wisconsin, USA cities. Science of the Total Environment, v.627, n.15, p.1453-1463, 2018. https://doi.org/10.1016/j.scitotenv.2018.01.200

VASCONCELOS, B. D.; DOS SANTOS, M. L. L. M.; VILELA, M. M. O. P.; CARVALHO, T. D.; FONSECA, F. L. A.; DA SILVA, O. R.; JUNQUEIRA, V. B. C.; AZZALIS, L. A.; SOLDÁ, P. L. Áreas contaminadas por postos de combustível e medidas de remediação no município de São Bernardo do Campo. Revista Saúde e Meio Ambiente, v.3, n.1, p.73-83, 2014. 
YUAN, S.; LI, K.; CHEN, T.; BI, X.; WANG, Q. Soil contamination by polycyclic aromatic hydrocarbons at natural recreational areas in Delaware, USA. Environmental Earth Sciences, v.72, n.2, p.387-398, 2014. https://doi.org/10.1007/s12665-013-2959-x

ZELINKOVA, Z.; WENZL, T. The occurrence of 16 EPA PAHs in food - a review. Polyclyc Aromat Compendium, v.15, n.35, p.248-284, 2015. https://doi.org/10.1080/10406638.2014.918550

Recebido em: 10/07/2020

Aceito para publicação em:17/02/2021 